\title{
Animal Images in College Psychology Textbooks
}

\author{
Peter B. Field' \\ Psychologists for the \\ Ethical Treatment of Animals \\ Baltimore, Maryland
}

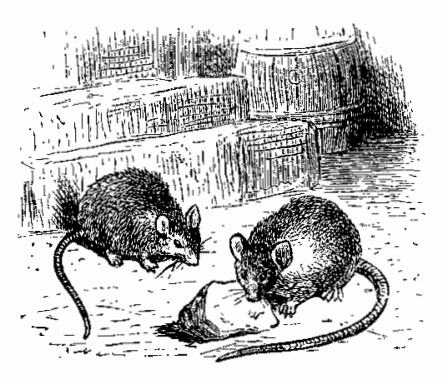

This article consists of three interrelated studies analyzing the presentation of animals and animal research in popular introductory college psychology textbooks. The introductory textbook is a good source for discovering the underlying and implicit attitudes about animals, since it plays a major and persuasive role in socializing students in scientific psychology.

Psychology textbooks unquestionably shape the attitudes of their readers, providing them with a conceptual framework for making sense of the actions of people and animals around them. If these textbooks portray animals chiefly as useful for experimentation, this may foster utilitarian and manipulative attitudes towards animals. Alternatively, if these textbooks take a more naturalistic and ethological approach, this may have very different consequences. It may foster respect for animals as beings with their own unique behaviors and feelings, worthy of being understood and valuable in their own right. This viewpoint would be a less behavioral, mechanistic, and detached one. It would provide a conceptual framework for understanding topics that have had little interest to experimentalists: companionate relationships with

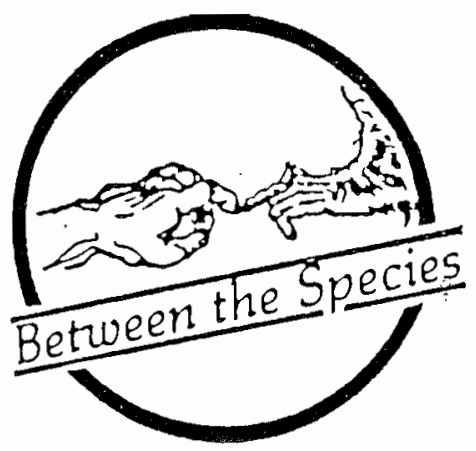

animals, individual differences among animals, empathy with animals, and so on.

\section{Contrasting High- and Low-invasive College Textbooks}

The purpose of this section is to investigate the attitudes toward animals presented in popular introductory textbooks in psychology, using a measure of the invasiveness of the animal research they discuss. The concept of invasiveness in animal experimentation attempts to specify statistically the degree of pain, distress, and long-term harm resulting from an experiment. Shapiro and Field (1987), among others, have developed such a scale for use in content analysis of published research articles, research proposals, and other material. They developed a 6-point scale covering the whole range of invasiveness, ranging from a high level in electric shock, radical surgery, or extreme deprivation, down to studies involving only a low or negligible level of invasiveness, such as naturalistic observation, simple behavioral tests, or conditioning without distress. This scale has been used to chart changes in degree and type of invasiveness in animal research over the past 40 years (Field, 1988), and the invasiveness of research conducted by the leaders of psychology's animal research committee (Field, Shapiro, \& Carr, 1990).

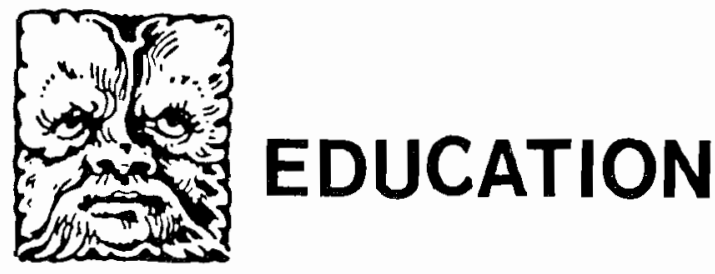




\section{Methods}

A sample of college psychology textbooks was selected from a comprehensive directory of introductory texts in psychology (Taney, 1986). In order to make sure that widely-used, well-accepted current textbooks were sampled, only textbooks that had gone through 5 or more editions were chosen. All of the textbooks meeting those criteria were ordered, and a sample of 11 textbooks was obtained by the cutoff date for the study. The complete list of texts used is referenced in Table 1.

All references to animals in the texts were then copied in summary form, and the research studies reported were scored from the summary sheets for degree of invasiveness by a trained rater. Only a portion of all the references to animals were to research studies or to experiments. In order to provide a reliability check, one of the books was scored twice without the rater's being aware that duplicate scoring sheets had been prepared for one of the books. Next, overall invasiveness ratings were obtained for each book by averaging the ratings. Finally, the highest and lowest invasiveness texts were selected and contrasted qualitatively for any differences in content that might help account for their differing scores.

\section{Results and Discussion}

The reliability for scoring each mention of a research study for invasiveness was $r=.82, N=60$, significant at the .001 level. Table 1 shows the mean ratings for the textbooks in this study, arranged in order from high to low invasiveness. The mean invasiveness rating was 2.71 , with a standard deviation of 0.31 , indicating that college textbooks present a range of studies on animals averaging moderate invasiveness. In order to determine whether any textbook was exceptionally high or low in invasiveness, $95 \%$ confidence limits were placed on the mean, using $t$ with $10 d f=2.23$ times the standard deviation, giving limits ranging from 2.02 to 3.40. All 11 textbooks fell within these limits. This indicates that we are not dealing with one group of high-invasive and a second group of low-invasive textbooks; instead, all textbooks report on some studies that are high and others that are low on this dimension.

Even though we cannot be sure statistically that we can identify unusually high or low invasive textbooks, nevertheless the next step in the research was to compare the two books that fell at the high and low ends of the range. The "high-invasive" textbook (Silverman, 1985), averaged 3.30 on a 6-point scale, while the "lowinvasive" textbook (McMahon \& McMahon, 1986),

\section{Table 1}

Invasiveness ratings of animal research cited in 11 college textbooks. A high score signifies higher invasiveness.

$\begin{array}{lrr}\text { Textbook } & \begin{array}{r}\text { Mean } \\ \text { invasiveness }\end{array} & \begin{array}{r}\text { Number } \\ \text { of studies }\end{array} \\ \text { Silverman (1985) } & 3.30 & 23 \\ \text { McConnell (1986) } & 2.95 & 43 \\ \text { Kagan \& Segal (1988) } & 2.93 & 46 \\ \text { Kimble, Garmezy, \& Zigler (1984) } & 2.92 & 60 \\ \text { Bourne \& Ekstrand (1985) } & 2.90 & 39 \\ \text { Bootzin, Bower, Zajonc, \& Hall (1986) } & 2.64 & 47 \\ \text { Zimbardo (1985) } & 2.58 & 55 \\ \text { Fernald \& Fernald (1985) } & 2.46 & 71 \\ \text { Kalish (1986) } & 2.43 & 7 \\ \text { Morgan, King, Weisz, \& Schopler (1986) } & 2.42 & 31 \\ \text { McMahon \& McMahon (1986) } & 2.28 & 67\end{array}$


averaged 2.28, a difference of about 1 scale point on a 6-point scale. Even though this is a small difference, it may nevertheless be fruitful to contrast these two texts not only in their treatment of animals, but to determine if they differ on topics that seemingly have nothing to do with animal issues.

The obvious first point of comparison is their attitudes toward animal experimentation. Does the invasiveness scale enable us to predict attitudes toward animals extending beyond the narrow issue of invasiveness? First, consider the topic of ethics in animal experimentation. Does the more invasive text have a weaker statement on protecting animals in research settings than the less invasive text? Actually, the high-invasive text has no statement at all on ethics in animal experimentation, while the low-invasive text spends several paragraphs on this, confiding that

... we love the field of psychology. But some studies we report make us cringe, since on the surface they seem unnecessarily cruel. In many cases, though, we are not in a position to decide whether the research results justify the methods used in the experiment (p. 23).

This is the only text examined that concludes that animal experimentation may sometimes be cruel and in need of improvement from the standpoint of animal welfare. This text makes clear to the student that research results must justify the methods used, an advance over the typical silence on this point. The success of the invasiveness scale in picking out the one text that voices any doubts about experimentation is an argument for its validity.

Furthermore, this is the only text surveyed that actually cites a specific research project and questions the ethics of conducting it. On p. 277 the authors discuss an experiment on cooling rats to a body temperature of 5 degrees $\mathrm{C}$. in order to study performance. The authors state

... some researchers have called into question the ethics of performing the experiment.... Nevertheless, the experiment was performed, so we should at least use its findings rather than have the unpleasant thing be for naught.

The high-invasive text voices no reservations whatsoever about any animal research project.
Can we find any indications of an opposite attitude toward animals in the high-invasive text, one of indifference to the plight of suffering animals, or even treating this issue in a humorous way? In the highinvasive text, but not in the other book, we find a section headed "Conditioning before Pavlov," (p. 135) representing an extract from a play written about the year 1615 , describing how a monk doing penance by eating off the floor made sure that a group of cats would not steal his food:

I put them all in a sack, and on a pitch black night I took them out under an arch. First I would cough and then immediately whale the daylights out of the cats. They whined and shrieked like an infernal pipe organ. I would pause for a while and then repeat the operation-first a cough, and then a thrashing... Thereafter, whenever I had to eat off the floor, all I had to do was to cough, and how the cats did scat!

Regrettably, this is not presented with any comment that might enable the college sophomore to put it in context. Some students might think it an interesting finding that deserves follow-up. There is no comment about the obvious displacement of aggression in which the monk takes out his penance-induced frustrations on the cats. Obviously the author thinks that beating cats calls for no explanation, so long as it makes a telling theoretical point. This anecdote, incidentally, was told in two of the other textbooks studied.

Plainly, the two texts differ dramatically in attitudes toward some aspects of animal welfare. Differences in the training of the authors might cast some light on this: the author of the high-invasive textbook studied under two groups of experimental psychologists, while the two authors of the low-invasive text mention no training or interest in experimental psychology, but cite interests in counseling, testing, teaching, and consultation. The clinical orientation of the low-invasive authors might help explain their greater use of empathic approaches to animals.

Next, a count was made of all the different species referred to in the two texts. The high-invasive text referred to 13 species, while the low-invasive text mentioned 46 species, over 3 times as many. The lowinvasive text has a much wider range of interest in animals, uses them to make more points, and mentions 
species that are not ordinarily seen in the laboratory: elephant, deer, grasshopper, rattlesnake, sheep, etc. The high-invasive text sticks to standard experimental animals, while the low-invasive text is more sensitive to and comfortable with the wide range of animal species and with species-specific behavior.

Next, a comparison was made of the activities engaged in by the animals in the two textbooks. The activities in the high-invasiveness text were those that might be expected in a laboratory: learning, being conditioned or imprinted, thinking, manipulating puzzles, or looking. In the low-invasive text animals engaged in a wider range of behavior, as would be expected from the broader range of species mentioned and from the greater tendency to cite studies in naturalistic settings. In addition to the behaviors mentioned in the high-invasive text, they showed yawning, staring, hoarding, displaying rhythms, doing territorial marking, and imitating. The low-invasive text uses this broader range of animal behavior to make it clear that animals have special powers such as infrared receptors in snakes and receptors for flowers in bees. These findings suggest a broader characterization of the concept of "low invasiveness:" it refers to the study of animal behavior in the natural setting as well as the absence of pain, distress, or long-term harm.

Do the textbooks differ in areas that have nothing to do with animals? One area that might show differences is in attitudes toward borderline areas of science or pseudo-science. Perhaps the high-invasive text would betray an attitude of skepticism, disinterest, and disdain by avoiding these topics, while the lowinvasive text would show a broader range of tolerance for the disreputable and unconventional. The lowinvasive text did in fact mention the following borderline areas that were absent in the other text: acupuncture, palm reading, Houdini's escapes, astrology, phrenology, extrasensory perception, and near-death experiences. Similarly, in the discussion of hypnosis, the low-invasive text mentioned topics replete with fascination and questionable reputation: Mesmer, group contagion, walking on hot coals, stage hypnotism, and the possibility of inducing immoral acts by hypnosis. The high-invasive text avoided these topics, instead reporting a typically academic experiment on inducing different moods by hypnosis to study variations in learning word lists. The high-invasive text treats hypnosis with such skepticism that it even makes a possibly Freudian error in citing Barber's Hypnosis:
A scientific approach; the word "hypnosis" is left out of the title (p. 520), leaving only "A scientific approach." The high-invasive text seems conservative and skeptical, perhaps dogmatic, in its treatment of areas of borderline respectability. In contrast, the low-invasive text is less prejudiced and quite open to unconventional topics, those lacking academic cachet. This orientation also slyly suggests that perhaps scientific psychology is not quite as far from its discredited mystical and magical predecessors as it would like to think.

Another area of comparison can be found in the issue of the individual's relationship to psychiatric treatment. The high-invasive text did not discuss the individual's right to refuse treatment, but instead detailed drug and electroshock treatments without mentioning their drawbacks, contraindications, or the possibility that an individual might not want to undergo them. The highinvasive text mentioned by name a variety of neuroleptics, mood stabilizers, anti-depressants, and anti-anxiety agents, while the low-invasive text mentioned very few. By contrast, the low-invasive text discussed involuntary treatment, patients' rights, deinstitutionalization, and the rights to refuse drugs, to a hearing, and to the least restrictive alternative treatment. It mentioned psychosurgery and lobotomy very critically, an area not discussed in the high-invasive book. It noted that electroshock therapy, although sometimes effective, is used indiscriminately, may result in brain damage, and does not come to grips with the patient's problem. In summary, the low-invasive text took a strongly liberal attitude toward individual rights in the face of possible abuses by powerful social agencies. This seems consistent with defending other helpless organisms-animals-against excesses by scientific authority. It also indicates a skepticism about physical and drug methods of treatment for psychological problems (after all this is a text on psychology, not psychiatry). Since the invasiveness scale is heavily weighted with drug, surgical, and shock procedures, it is not surprising to find consistency between approaches to animals and to humans on these indicators. The highinvasive text believes that the doctor knows best in handling psychiatric problems, while the low-invasive text focuses more on the individual's rights against even benevolent authority.

These results suggest differences in social attitudes between the two textbooks. Previous research has shown that individuals identified with the animal rights movement support other liberal causes. For example, a 
survey of 853 subscribers to an animal-rights magazine, The Animals'Agenda, showed that more than $80 \%$ were also identified with the environmental movement, the civil rights movement, the feminist movement, the antiapartheid struggle, and anti-war or anti-nuclear movements (research by Rebecca Templin Richards, in Bartlett, 1991). Similarly, congressmen who endorse animal protection bills were rated as supporting civil liberties and human rights, while congressmen who opposed such bills tended to favor the needs of corporations, national defense, and curbs on federal spending (Kimball, 1989). These results are in agreement with the attitudes revealed in the college textbooks - a tendency for the low-invasive text to take liberal social attitudes, while the high-invasive text seemed more nearly conservative. A word of caution on the generality of these results: it is not clear just how far we can generalize these findings, since only further research can indicate if they are limited to the two textbooks studied.

\section{Comparison with Two Other Textbooks}

In order to explore these findings further, two textbooks from the 1970's were selected arbitrarily for comparison. The senior author of the first text was a well-known animal experimentalist (Krech, Crutchfield, \& Livson, 1974); the other text was an earlier edition (McMahon, 1977) of the low-invasive textbook previously analyzed. Although these two textbooks had a core of animal-centered material in common, they differed in other ways. The text by Krech et al. seemed to emphasize the usefulness of animals as subjects for experiments, while the McMahon text tended to emphasize animals as more self-directed, as more human-like, and more as companions for people.

The McMahon text took seriously the possibility of animal communication with humans. It discussed communication between humans and dolphins, and showed a photo of an ape operating a multiple-response keyboard, while Krech did not discuss these issues. McMahon also took seriously the possibility that an ape could be an artist, showing a photograph of a chimpanzee working with paints; Krech ignored such messy topics. McMahon dignified the aniunal by taking seriously its communicative and artistic potentialities, imputing higher or even human-like abilities to it, while the other book kept the animal at an animal level.

The McMahon text discussed the operantconditioning techniques used with apes at the Portland
Zoo to enhance interactions and reduce boredom. The other textbook omitted this topic and instead discussed animals largely as material for experimentation. Krech mentioned Miller's research with curare, Lashley's brain injury studies, morphine addiction in chimpanzees, electroconvulsive shock in mice, and electric shock as punishment, none of which appeared in the McMahon book, and all of which are highly invasive. On the other hand, McMahon did show a photograph of an "executive" monkey restrained for an ulcer-producing study.

The graphic material in the texts was also consistent. McMahon showed several photos of animals in a companionate relationship with humans, while Krech showed no animals with human beings except a dog in harness with Pavlov and his assistants. His other graphic material tended to treat animals as passive objects. For example, he printed a photo of a rat on a jumping stand, with the rat a tiny spot and the jumping stand much larger. In other pictures a tiny rat was shown in a large maze, suggesting that the animal could be reduced to a dimensionless point, with conditioning producing and explaining its behavior, making each animal identical and interchangeable with all others. This book also used animals as mere silhouettes for testing eidetic imagery, as designs for teaching reading, or vanishing into hidden cut-up figures.

By contrast, McMahon showed naturalistic photos of a sheep and of a dormouse in comfortable poses looking directly at the camera, with no implication that they were about to take part in experiments. The dormouse face was made large and emphatic, as if to suggest that you could read its emotions and feelings or reach out and touch it. The implicit message in the McMahon text was that animals have feelings, personalities, and relationships, like humans. The Krech text, on the other hand, portrayed animals as passive, interchangeable, materials for research, not human-like, and never in a companionate relationship with humans. These books obviously differ on some of the attitudes towards animals identified by Kellert (1980), such as humanistic, naturalistic, scientistic, etc.

\section{Conclusions}

The comparison of these latter two texts provides additional information supplementing the former comparison of the high and low invasiveness texts. In both comparisons the experimental or high invasive texts took a utilitarian, intellectual, and mechanistic attitude toward animals, while the naturalistic or low- 
invasive texts took a more respectful and empathic attitude toward animals. One orientation sees animals as useful only for the experimental findings they generate, the other attitude sees animals as intrinsically interesting beings. One attitude is naturalistic and ethological, the other experimental and manipulative. Suggestive and preliminary evidence was also developed that these attitudes are related to other social attitudes, such as the conservative-liberal dimension.

\section{Harlow's Monkeys in College Textbooks}

Previous research (Field, 1990) has noted that psychology textbooks sometimes spare undergraduates the details of stressful research conducted by prominent experimentalists. For example, Selye's theories on stress were reported in all textbooks surveyed, while only 4 of 11 texts discussed his prolific and stressful animal experiments. Similarly, when Richter's research on forcing rats to swim to exhaustion is mentioned, Zimbardo (1986, p. 459) states only that the rats were placed "under extreme, frightening stress" but does not say how this was done. McMahon and McMahon (1986, p. 532) cite Richter but refer merely to animals put in "hopeless situations." This suggests a tendency to sanitize or minimize details of stressful research while separating these details from the theoretical generalizations they produced, a maneuver reminiscent of psychodynamic defenses against threat. Can this tendency be identified in another experimental area? Specifically, is primate maternal-deprivation research presented pictorially as less stressful than it really is?

This section analyzes how introductory psychology textbooks present the research on maternal deprivation in infant monkeys conducted by the late Harry Harlow and his associates. The purpose is neither to review nor to criticize Harlow's work but to use it as a case example of how stressful research is presented to the beginning student. Indirectly, this analysis should cast light on the beliefs and culture of animal research through its strategy of presenting a research topic at the elementary level, much as Churchill (1988) and Massey (1988) have analyzed the presentation of humanistic psychology in general textbooks.

Maternal deprivation experiments were conducted on more than 1000 primates (Stephens, 1986). The basic paradigm involved separating a newborn monkey from its mother and studying its reactions to isolation (e.g. clinging to surrogate mothers made of cloth or wire).
Some experiments used partial isolation conditions, in which the infant monkeys could see and hear other monkeys, but not interact with them. Other experiments used total isolation, including restricted sensorimotor stimulation, for as long as 6 months. Infant monkeys tended to cling to cloth surrogates in preference to bare wire surrogates, even when fed exclusively on the wire surrogates. Monkeys reared in isolation displayed devastating behavioral abnormalities as adults, including impaired social, sexual, maternal, and problem-solving behavior, huddling, self-clutching, and other bizarre behaviors (Stephens, 1986). Harlow also showed that some reversal in these abnormal behaviors could be obtained in some animals through persistent interaction with normal "therapist" monkeys. Experiments using prolonged social isolation in infant primates have been rated as "most severe" on a scale of invasiveness in animal experimentation (Shapiro \& Field, 1987), and were among those singled out as particularly distressing in a survey of painful animal research (Pratt, 1980).

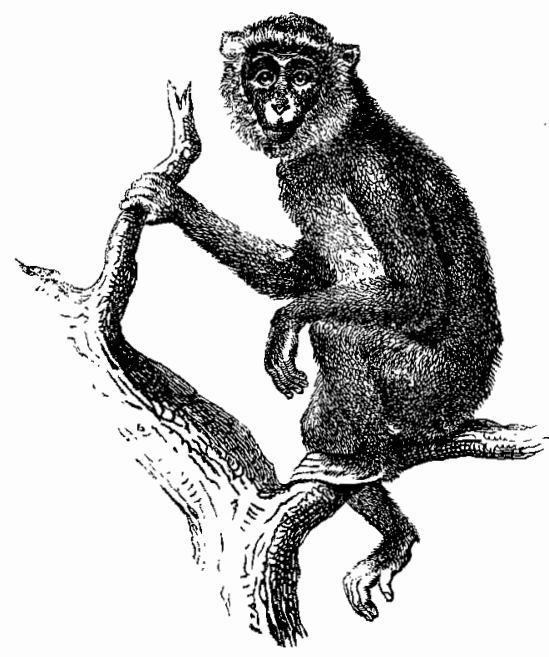




\section{Method}

A sample of 24 introductory psychology textbooks was selected (see appendix). The initial source was Taney's list of introductory textbooks in psychology. In order to obtain a sample with many mainstream and widely adopted textbooks, 12 texts that had gone through 5 or more editions were selected, and supplemented with all other recent psychology textbooks that were available in two local libraries. Books in the final sample were published between 1974 and 1988, providing ample time for coverage of Harlow's work, which began in the 1950's. The photographs and textual material were analyzed using simple counts of presence or absence.

\section{Results and Discussion}

Harlow's work was discussed in 23 of the 24 textbooks selected $(96 \%)$, suggesting that his work is highly regarded and suitable for presentation to undergraduates. The only textbook that did not index his work was Haber and Runyon (1986). Discussions ranged from one or two paragraphs to several pages.

A count was made of the favorable (or unfavorable) descriptions of the research, showing that 17 of 23 textbooks $(74 \%)$ used favorable terms to describe the research, with no unfavorable terms used. One or more of the following were used in these 17 textbooks: classic, intriguing, famous, interesting, dramatic, significant, rich insights, major advance, best, pioneering, important. Plainly, this research was presented to students with a high degree of approval.

The next question was whether certain features of Harlow's work that might be repugnant or disturbing to undergraduates were omitted. No textbook referred to, or showed photographs of, the confinement chambers designed to produce total isolation (which Harlow called "pits" or "wells of despair"). Also absent were references to or photographs of partial isolation cages. The "rape rack" (Harlow's term) was mentioned in only one textbook ( $4 \%$ of the total); it was used to restrain the female monkey for intercourse.

The severe results of social isolation and maternal deprivation were discussed in most textbooks ( 20 of 23 , or $87 \%$ ), but only 5 of 23 , or $22 \%$, showed pictures of the bizarre behavior of the isolated monkeys. These findings suggest that although the behavior disturbances were covered verbally, only a small minority of textbooks included photographs of these bizarre behavior patterns. This seems consistent with the avoidance of provocative images of confinement- chambers or mention of the "rape rack." No textbook cited the number of monkeys used in these experiments, although as noted above the total was more than 1,000 . The student could easily draw the conclusion that only a handful of monkeys had been used.

Six textbooks (26\% of the total) expressed strong ethical objections to conducting this kind of experimentation on humans, but no textbooks raised ethical questions about the use or monkeys, much less sympathy for or empathy with them. The strictly objective, behavioral descriptions served to distance the reader from the procedures and the results, and to blunt the potentially emotionally disturbing impact of these experiments. They socialize the student in clinical, scientific detachment, much as the physician learns detachment in the dissection room. Incidentally, Harlow himself occasionally expressed sympathy for the monkeys in his experiments (Stephens, 1986), but these comments were never cited in the textbooks.

The issue of how widely these findings could be generalized was usually ignored, although the student might easily conclude that wide applicability was likely. Only one textbook (Kagan \& Segal, 1988) raised a question about whether these results could be validly generalized even to other monkey species.

The overwhelming majority of the textbooks ( 19 of 23 , or $83 \%$ ) showed appealing pictures of an infant monkey clinging to a cloth surrogate mother for comfort and reassurance. These photos showed open settingsthey never seemed to show confinement, bars, mesh, sheets of metal, or cage-like walls. The surrogate mother looked like a big doll, with enormous round eyes and a smiling mouth. This pervasive image is a lasting one. It directs the student away from the effects of isolation onto theoretical issues of drive reduction and contact comfort. Although the monkey may be frightened, the picture shows no psychotic behavior or gross abnormalities. Naturally, there are no photos of experimenters snatching an infant away from its mother. The student may be pardoned for missing the fact that infant monkeys reared with only a cloth surrogate also show social deficits-total isolation is not necessary.

The surrogate mother looks so clown-like"bizarre" (Krech, Crutchfield, \& Livson, 1974), with a "silly wooden head"(McConnell, 1986) -that it suggests that something amusing and enjoyable is going on. The clown-like mother image shifts the proceedings froin serious to playful, from tragedy to comedy, from grim reality onto a plane of humorous unreality. It is no 
surprise that Harlow's accounts of his experiments are adorned with a wry humor (already displayed in his phrase "rape rack"), as if to minimize the disturbing realities he produced. The student may well absorb the unspoken message that a light and playful attitude is the correct way to handle tragic emotional situations, a poor foundation for a later career in counseling.

The cute photographs of the baby monkey make it look like a toy or a plaything. In fact, in some of the textbooks ( 5 of 23 , or $22 \%$ ), photos show a mechanical toy frightening the baby monkey and leading it to jump onto the cloth surrogate. This menacing toy merely confirms for the student the playful and silly aspect of the monkey's behavior: in fact, it reduces the monkey itself to a kind of silly toy, stupid enough to think a cloth doll is its mother and a mechanical bear is a dangerous threat. Instead of tragic maternal deprivation, some silly game or joke seems to be going on.

\section{Conclusion}

The graphic and textual material seem to present a sanitized, bland, or comical interpretation of this research. The limited presentation of stressful or confining procedures, the cute photos of baby monkeys, the glowing assessment of the value of the research, and the objective treatment of the results combine to minimize the severity of the procedures used, to defuse possible objections, and to hold up the research to undergraduates as a model of animal experimentation.

\section{Recommendations}

These findings do not imply that college textbooks should go to the other extreme and provide pictures of isolation chambers and rape racks. But there are other possible styles of presentation that may be more useful for meeting the needs of today's students, who are concerned with values as well as with the content of science. Alternative possibilities would include using Harlow's work as a means of learning empathy with distressed animals (Shapiro, 1988; Fox, 1988), and by extension, with distressed humans. As a relief from the pervasive behavioral tone, students could be asked to imagine the feelings of the infants and mothers in these experiments, or to role play mother and baby (and even the experimenter!). Students could be asked about their own feelings about personally conducting such research. Still another possibility would be to make explicit the moral dilemmas that are now merely implicit in Harlow's work-especially the right of scientific investigation vs. the right of animals to their own lives. Questions could be raised about cost to animals vs. benefits in knowledge, and whether further research of this type is warranted. Would institutional review boards permit this research today? What modifications might be required? Other value questions might include: whether less invasive methods could have been used in the first place, what are the limits of generalization from animals to humans, and whether research codes to protect animals are needed. Finally, the uniform praise accorded these experiments seems less appropriate when value dilemmas are being raised. If presented as material for discussion and controversy, students might come out with a more balanced view of Harlow's experiments.

\section{Textbook Treatment of Ethics in Animal Research}

In previous sections of this article there were occasional references to the treatment of ethical principles and controls in college tex tbooks. Notably, the high-invasive textbook omitted any mention of ethical principles in dealing with animals, while the low-invasive textbook discussed this fairly extensively. In Section II it was noted that authors of psychology tex tbooks never mentioned the ethics of conducting maternaldeprivation experiments with primates, although several warned against doing such experiments on humans.

These observations suggest that a broader survey of the presentation of ethics in introductory textbooks is in order, using the same sample of 11 textbooks as in Section I. Therefore, all statements on ethics in animal research in these texts were identified and analyzed as described below. All textbooks discussed the experimental method in psychology, so it might be expected that these textbooks would have statements about proper anesthesia, appropriate housing, sources of animals, techniques for minimizing discomfort or distress, the role of review committees, etc.

The actual statements on ethics in animal experimentation were either nonexistent or lacking in specifics. If ethical principles were discussed at all, they tended to be generalities that psychological research is proceeding in humane fashion, with adequate protection for the animals.

Specifically, 5 of the 11 textbooks surveyed do not mention the ethics of animal research: Silverman (1985), Kalish (1986), Zimbardo (1985), McConnell 
(1986), and Morgan, King, Weisz, and Schopler (1986). Bourne and Ekstrand (1985, p. 27) do at least state that there are accepted ethical principles for the humane care and treatment of research animals, but do not say what they are. This same textbook does outline in some detail ethical principles for research on humans ( $p .26$ ), as do a number of other texts. Fernald and Fernald (1985, p. 52) state that guidelines have been established for surgery on animals, but like the previous authors, fail to say what they are. Kagan and Segal (1988, p. 34) state that charges of animal abuse leveled at psychologists are groundless, and moreover, animal research has made impressive contributions. They go on to say that the American Psychological Association (APA) requires its members to "take special care in the use of animals in psychological research, avoiding needless harm and exploitation." However, these authors do not explain how needless harm and exploitation are to be avoided, and give no specifics about principles that might protect animals.

As noted in Section I of this article, McMahon and McMahon (1986) raise an ethical objection to a particular animal study (p. 277), a very unusual event in a psychology textbook. They also state (p. 23) that

\section{... there are no detailed, specific formal guidelines in the United States for animal experimentation in any science. The early 1970s heard a hue and cry about human experimentation which resulted in a set of formal principles. It seems that 1984 was a year of the same type of movement, but aimed at animal treatment.}

Actually, it would have been possible to cite some previous guidelines by APA and other animal research groups, so this statement seems unduly negative. In any case, these authors go on to state that research results should justify the methods used, and they express hope for better control over the treaument of animals ( $p p$. 23-24). Although these authors express genuine concern for animals in psychology, they neglect to quote available detailed standards and controls and seem unaware of them.

Bootzin, Bower, Zajonc, and Hall (1986, pp. 34-35), provide a feature on ethics in animal experimentation, including a reprise of the Taub case, but their statement is also very thin on specifics:

\begin{abstract}
Ethical standards prohibit the researcher from inflicting unnecessary pain.... Psychological research... must be subject to rigorous ethical constraints.... State and federal regulations specify procedures and standards for animal care-housing, feeding, and cleaning.
\end{abstract}

Perhaps the strongest statement is provided by Kimble, Garmezy, and Zigler (1984, p. 660), since they simply reprint "Care and Use of Animals," from the Ethical principles of psychologists (APA, 1981). But no textbook reprints or quotes from APA's more extensive and more stringent statement, Guidelines for Ethical Conduct in the Care and Use of Animals (APA, 1985), even though 6 of these textbooks were published after 1985 .

In the light of a global animal-rights movement vigorously questioning practices of psychological research, the failure of these textbooks to address ethical issues in this area more directly is surprising. Still more surprising is the fact that these textbooks lag far behind the official APA Guidelines, which after all reflect not radical viewpoints but mainstream scientific standards. Animal advocates would question whether these Guidelines go far enough in protecting animals.

\section{Recommendations}

Plainly, a strong and meaningful ethical statement is needed, one that deals specifically with appropriate research practices and how they are enforced. Students should be told that ethical questions have been raised about some invasive research, and that other approaches to animal research are legitimate and equally "scientific." Statements on ethics in research with humans need to be broadened to deal with animals.

But improved ethical statements are only a portion of the many changes that such textbooks need to make in dealing with animals. The attitudes, emphases, and graphics of the high-invasive texts need to be changed in the direction of the low-invasive texts. One specific example of some of the many changes needed would be references to empirical findings on the use of psychology to benefit animals, as in the application of operant conditioning to ease boredom among zoo animals (McMahon \& McMahon, pp., 220-221). Other findings that might be instructive to students include the relationship between childhood cruelty to animals and later aggressive criminality (Felthous \& Kellert, 1987). Also worth mentioning are findings about 
improvement of research practices reported for example in Humane Innovations and Alternatives in Animal Experimentation. At a theoretical and philosophical level, the work of authors such as Peter Singer, Tom Regan, Bernard Rollin, Michael Fox, and many others might deserve mention, especially as a counterbalance to the prevailing conservative, medical, and experimental viewpoints about animal research.

\section{References}

American Psychological Association (1981). "Ethical principles of psychologists." American Psychologist, 36, 633-638.

American Psychological Association (1985). Guidelines for ethical conduct in the care and use of animals. Washington: Author.

Bartlett, K (1991). "Survey shows movement promise." The Animals'Agenda, 11, March, 2 (editorial).

Churchill, S. D. (1988). "Humanistic psychology and introductory psychology textbooks: Wizards and straw men." Paper presented at American Psychological Association Annual Convention, Atlanta, GA.

Felthous, A. R., \& Kellert, S. R. (1987). "Childhood cruelty to animals and later aggression against people: A review." American Journal of Psychiatry, 144: 710-717.

Field, P. B. (1988). "Surveying the behavior of researchers with a scale of invasiveness." Paper presented at the American Psychological Association Annual Convention, Atlanta, GA.

Field, P. B. (1990). "The most invasive animal experiments in psychology textbooks." PsyETA Bulletin, 9 (2), 6-8.

Field, P., Shapiro, K., \& Carr, J. 'Invasiveness of experiments conducted by leaders of psychology's animal research committee (CARE)." PsyETA Bulletin, 10 (1), 1-10.

Fox, M. W. (1988). "Beyond animal rights: Feeling, caring, and the golden rule." PsyETA Bulletin, 7 (2), 1-4.

Kellert, S. (1980). “American attitudes toward and knowledge of animals: An update." International Journal for the Study of Animal Problems, 1 (2), 87-119.

Kimball, R. (1989). "Liberal/conservative voting records compared to interest in animal protection bills." PsyETA Bulletin, 9 (1), 7-9.

McMahon, F. B. (1977). Psychology: The hybrid science (3rd ed.). Englewood Cliffs, NJ: Prentice-Hall.

Massey, R. E. (1988). "Impact of humanistic psychology on personality, clinical and counseling texts." Paper presented at American Psychological Association Annual Convention, Atlanta, GA.

Pratt, D. (1980). Alternatives to pain: In experiments on animals. New York: Argus Archives.

Shapiro, K. J. (1988). "Understanding dogs through history, social construction, and kinesthetic empathy." Paper presented at American Psychological Association Annual Convention, Atlanta, GA.

Shapiro, K. J., \& Field, P. B. (1987). "A new scale of invasiveness in animal experimentation." PsyETA Bulletin, 7 (1), 5-8.

Stephens, M. L. (1986). Maternal deprivation experiments in psychology: A critique of animal models. Jenkintown, PA: American Anti-Vivisection Society.

Taney, S. (1986). "Directory of introductory psychology texts in print: 1986." Teaching of Psychology, 13, 42-45.

\section{Notes}

${ }^{1}$ Supported by grants from the Luster Family Foundation, the New England Anti-Vivisectionist Society, and the Scientists Group for Reform of Animal Experimentation to Psychologists for the Ethical Treatment of Animals.

I thank Kenneth J. Shapiro, Martin L. Stephens, and Randall Lockwood for helpful suggestions. Author's address: 2401 Hillhouse Road, Baltimore, MD 21207.

\section{Appendix}

Baron, R., Byrne, D., \& Kantowitz, B. (1978). Psychology: Understanding behavior. Philadelphia: Saunders.

Bootzin, R. R., Bower, G. H., Zajonc, R. B., \& Hall, E. (1986). Psychology today: An introduction (6th ed.). New York: Random House.

Bourne, L. E., Jr., \& Ekstrand, B. R. (1985). Psychology: Its principles and meanings (5th ed.). New York: Holt, Rinehart \& Winston.

Davidoff, L. (1980). Introduction to psychology (2nd ed.). New York: McGraw-Hill.

Desiderato, O., Howison, D. B., \& Jackson, J. H. (1976). Investigating behavior: Principles of psychology. New York: Harper \& Row.

Eysenck, H. J., \& Wilson, G. D. (1976). A textbook of human psychology. Baltimore: University Park Press.

Fantino, E., \& Reynolds, G. S. (1975). Introduction to contemporary psychology. San Francisco: Freeman.

Fernald, L. D., \& Fernald, P. S. (1985). Introduction to psychology (5th ed.). Dubuque, IA: Brown. 
Gerow, J. R. (1986). Psychology: An introduction. Glenview, IL: Scott Foresman.

Haber, A., \& Runyon, R. P. (1986). Fundamentals of psychology (4th ed.) New York: Random House.

Hilgard, E. R., Atkinson, R. C., \& Atkinson, R. L. (1975). Introduction to psychology (6th ed.). New York: Harcourt Brace Jovanovich.

Kagan, J., \& Segal, J. (1988). Psychology: An introduction (6th ed.). New York: Harcourt Brace Jovanovich.

Kalish, R.A. (1986). The psychology of human behavior. (5th ed.). Monterey, CA: Brooks/Cole.

Kimble, G.A., Garmezy, N., \& Zigler, E. (1980). Principles of general psychology. (5th ed.). New York: Wiley.

Krech, D., Crutchfield, R.S., \& Livson, N. (1974), Elements of psychology (3rd ed.). New York: Knopf.

Landy, R.J. (1984). Psychology: The science of people. Englewood Cliffs, NJ: Prentice-Hall.

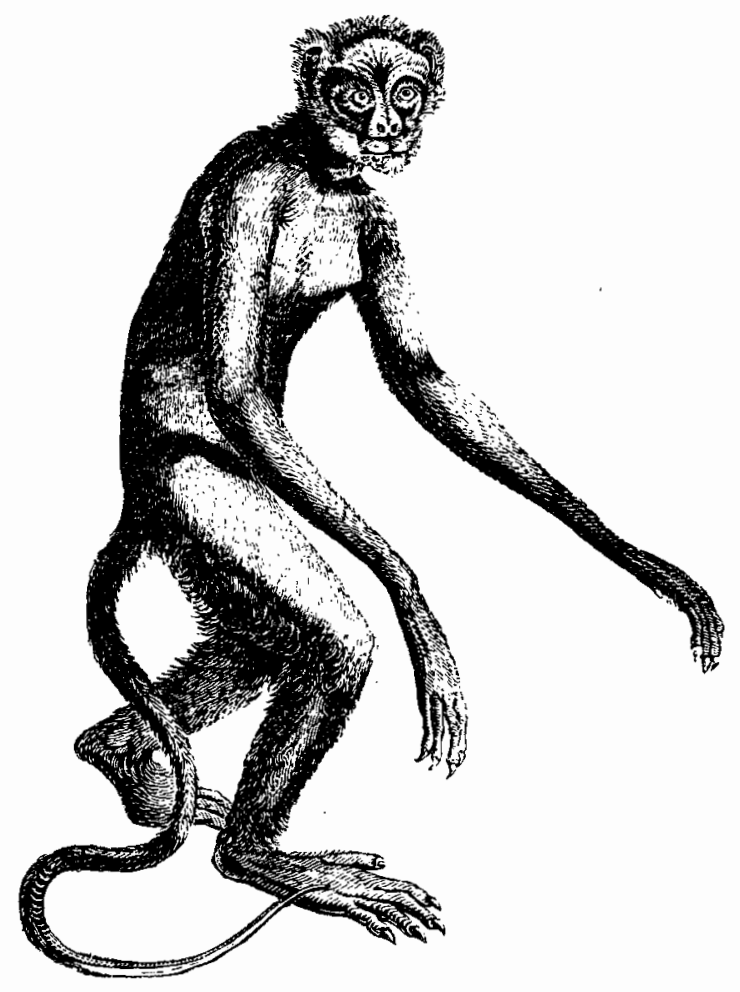

McConnell, J.V. (1986). Understanding human behavior (5th ed.). New York: Holt, Rinehart \& Winston.

McMahon, F.B., \& McMahon, J.W. (1986). Psychology: The hybrid science (5th ed.). Chicago: Dorsey.

Mische1, W., \& Mische1, H.N. (1980). Essentials of psychology. (2nd ed.). New York: Random House.

Morgan, C.T., King, R.A., Weisz, J.R., \& Schopler, J. (1986). Introduction to psychology (7th ed.). New York: McGraw-Hill.

Rubin, Z., \& McNeil, E.R. (1985). Psychology: Being human (4th ed.). New York: Harper \& Row.

Silverman, R.E. (1985). Psychology (5th ed.). Englewood Cliffs, NJ: Prentice-Hall.

Whittaker, J.O. (1976). Psychology of moder life. New York: Human Sciences Press (Behavioral Publications, Inc.)

Zimbardo, P.G. (1988) Psychology and life (12th ed.). Glenview, IL: Scott Foresman.

\section{Predators}

Night is almost day. Trees are red and gold, the deer are uneasy. Her silk cat feet move silently. She has searched a long time. The mice and squirrels are quick. She is tired and small.

He drains the last of the beer. Can is crushed and tossed aside. Leaves are crisp with frost; They break easily beneath his boots. He turns up his collar against morning, and cradles the gun like a child.

A death scent startles her. Their eyes meet in confusion. The sound shatters daylight, frightening martens and jays. Silk feet moving silently, the bobcat falls.

Kathleen Malley 